\title{
A Study on the Control Method Without Stratification of Single Duct VAV Terminal Units
}

\author{
Hyo-Jun Kim ${ }^{1}$, Su-Hyun Kang ${ }^{2}$ and Young-Hum Cho*³ \\ ${ }^{1}$ Graduate Student, Department of Architectural Engineering, Graduate School of Yeungnam University, Korea \\ ${ }^{2}$ Mechanical Engineering Division, HANA Consulting Engineers, Korea \\ ${ }^{3}$ Assistant Professor, School of Architecture, Yeungnam University, Korea
}

\begin{abstract}
The objective of this study was to propose a stratification control method for the minimum air flow of a variable air volume (VAV) terminal unit. The minimum air flow rate of the VAV terminal unit is the key factor affecting thermal comfort, indoor air quality (IAQ), stratification and energy consumption depending on the operating mode of the VAV system. Therefore, selecting the proper minimum air flow is very important. In this study, a building simulation was conducted to evaluate the indoor thermal comfort, stratification, IAQ and energy consumption according to the fixed minimum air flow rate of the VAV terminal units. In addition, an algorithm was proposed considering the stratification and variable minimum air flow rate depending on the indoor load. The results of the fixed minimum air flow rate simulation showed that the minimum air flow rate considering stratification satisfies all the conditions of indoor thermal comfort, IAQ and without stratification. The proposed method was found to be more effective than the existing control method. The energy comparison with the existing control method showed that the proposed method reduces the energy consumption.
\end{abstract}

Keywords: variable air volume system; minimum air flow; terminal unit; stratification; energy consumption

\section{Introduction}

The minimum air flow of a variable air volume (VAV) terminal unit is the key factor affecting the thermal comfort, indoor air quality (IAQ), stratification and energy consumption. A terminal unit with conventional control sequences can cause occupant discomfort or waste energy. The terminal unit will perform simultaneous heating and cooling, and the AHUs will consume more fan power if the minimum air flow is higher than required. On the other hand, the air conditioned space will have IAQ problems with less air circulation if the minimum air flow is less than required. Therefore, selecting the appropriate minimum air flow is very important in a VAV system. The existing minimum air flow of a VAV terminal unit generally applies approximately $30 \sim 50 \%$ of the maximum air flow as a fixed value.

Engdahl et al. (2004) evaluated the energy savings potential of a controlled supply air temperature of a VAV based system by a comparison with a constant supply air temperature. ${ }^{1)}$ Taylor et al. (2004) discussed

*Contact Author: Young-Hum Cho, Assistant Professor,

School of Architecture, Yeungnam University,

215, Dae-Dong, Gyeongsan, Gyungbuk 712-749, Korea

Tel: +82-53-810-3081 Fax: +82-53-810-3081

E-mail: yhcho@ynu.ac.kr

(Received October 8, 2014 ; accepted March 6, 2015 ) the minimum air flow setpoint of the terminal units. The actual controllable minimum air flow setpoint is normally different from the unit manufacturer's recommended minimum air flow setpoint for each unit size and for each standard control option. ${ }^{2}$ Cho et al. (2009) reported the relationship between the supply air temperature and minimum air flow. In addition, the relationship between the supply air volume and temperature that minimizes energy consumption was suggested through proper supply temperature, stratification and energy analysis according to the load, which can minimize energy consumption. ${ }^{3)}$

In the ASHRAE Standard 55, stratification that results in an air temperature at the head level that is higher than at the ankle level can cause thermal discomfort. ${ }^{4)}$ The difference between the room and supply air temperature should not exceed $8.4^{\circ} \mathrm{C}$ to avoid excessive temperature stratification. ${ }^{5}$ Wang et $a l$. analyzed the relationships between the heights of delaminating and the air supply temperature and velocity. ${ }^{6}$ Cho et al. (2010) identified a correlation between the minimum air flow and the discharge air temperature that will maintain room thermal comfort using a CFD simulation. The performance was conducted through a field experiment. ${ }^{7)}$ Liwerant (2008) suggested that the maximum leaving-air temperature (LAT) is $32.2^{\circ} \mathrm{C}$. An LAT above $32.2^{\circ} \mathrm{C}$ will result in stratification and/or short-circuiting. To maintain an LAT of $32.2^{\circ} \mathrm{C}$, the minimum (heating) air flow can be 
adjusted upward. These studies were conducted based on a certain height. ${ }^{8)}$

In this study, a comparison of the supply air temperature, flow rate and energy consumption according to the various heights was also performed. This paper proposes the minimum air flow of a VAV terminal unit that can resolve the IAQ and stratification problems based on a fixed minimum air flow. The comfort of the indoor load, indoor air quality, stratification and energy of the VAV terminal unit control method with a fixed minimum air flow was analyzed. The fixed minimum air flow of the VAV terminal unit, which is considered the most appropriate among the existing control methods, was then selected. The building energy simulation was carried out to evaluate the comfort, IAQ and energy consumption.

\section{Minimum Air Flow of a VAV Terminal Unit \\ 2.1 Control Sequence}

Terminal units are a critical component of VAV systems. They normally serve both interior zones, which only have a cooling load that will not require heating, and exterior zones, which will have a cooling and heating load that will require heating. The system consists of a controller, a temperature sensor, an actuator, a modulation damper, a heating coil and a flow station. For spaces requiring heating, a reheating coil can be installed in the discharge.

For the cooling cycle, the inlet damper modulates to maintain the room setpoint between the minimum and maximum air flow setpoint. For the heating cycle, as the temperature in the space decreases below the setpoint, the damper begins to close and reduces the flow of air to the space. When the air flow reaches the minimum limit, the valve on the reheat coil begins to open, as shown in Fig.1.

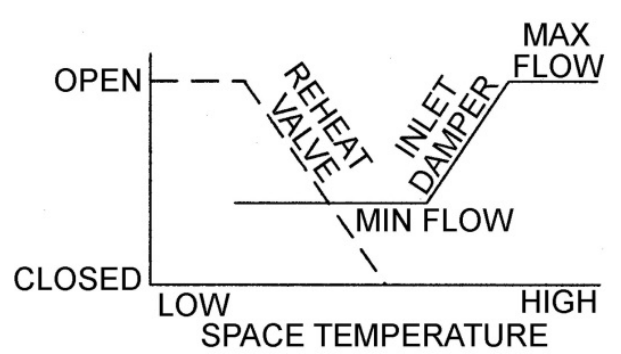

Fig.1. Control Sequence of the VAV Terminal Unit ${ }^{9)}$

The primary considerations for selecting the minimum air flow of the VAV terminal unit are the proper heating demand, amount of ventilation, energy, stratification, etc. These factors affect the indoor heat environment and its air quality. On the other hand, a VAV terminal unit control method with the minimum air flow fixed to $30 \sim 50 \%$ of its maximum air flow is currently used when cooling.

\subsection{Determined Minimum Air Flow ${ }^{7)}$}

\subsubsection{Minimum Air Flow for Heating Load}

The minimum air flow for a heating load is the air flow required by the room design heating load.
The minimum air flow needed to satisfy the building heating load requirement can be calculated using equation (1).

$$
\dot{\mathrm{V}}_{\text {min }, h}=\frac{Q_{h}}{\rho c_{p}\left(T_{s}-T_{r}\right)}
$$

Where, $Q_{h}$ is room heating load,

$\rho$ is standard air density,

$c_{p}$ is specific heat capacity,

$T_{s}$ is supply air temperature

$T_{r}$ is room air temperature, and

$\dot{V}_{\min , h}$ is air flow rate for heating load

\subsubsection{Minimum Air Flow for Ventilation}

The minimum air flow rate that satisfies the ventilation requirements can be calculated using Equations $(2) \sim(4)$. The outside air intake ratio can be calculated using the percentage of outside air in an AHU with Equation (2). The requirement of ventilation air flow in one zone can be calculated using the zone population and area with Equation (3).

$$
\begin{aligned}
& \alpha_{o a}=\operatorname{Min}\left(\operatorname{Max}\left(\frac{T_{r}-T_{s}}{T_{r}-T_{o a}}\right), 1\right) \\
& \dot{\mathrm{V}}_{f}=\frac{\left(R_{p} P_{z}+R_{a} A_{z}\right)}{E_{z}} \\
& \dot{\mathrm{V}}_{\text {min,v }}=\frac{\dot{V}_{f}}{\alpha_{o a}}
\end{aligned}
$$

Where, $\alpha_{o a}$ is AHU outside air intake ratio,

$T_{o a}$ is outside air temperature, minoa is minimum outside intake ratio, $\dot{V}_{f}$ is air volumetric flow rate for outdoor air requirement,

$R_{p}$ is outdoor air flow rate required per person as determined from Table 6-1 ASHRAE Standard 62.1,2009,

$R_{a}$ is outdoor air flow rate required per unit area as determined from Table 6-1 ASHRAE Standard 62.1,2009,

$P_{z}$ is zone population,

$A_{z}$ is zone floor area,

$E_{z}$ is zone air distribution effectiveness as determined from Table 6-2 ASHRAE Standard $62.1,2009$, and $\dot{V}_{\text {min, }}$ is air volumetric flow rate for ventilation

\subsubsection{Minimum Air Flow Requirement}

The minimum air flow setpoint can be set so that it equals either the highest air flow rate required by the room design heating load or the minimum rate required for ventilation.

$$
\dot{\mathrm{V}}_{\text {min }}=\max \left(\dot{V}_{\min , h}, \dot{V}_{\min , v}\right)
$$

Where, $\dot{V}_{\min }$ is minimum air volumetric flow rate

\subsection{Energy Consumption ${ }^{7}$}

Energy consumption is compared between the existing and proposed minimum air flow setpoints. 


\subsubsection{Cooling Energy Consumption}

The cooling energy consumption can be calculated using Equation (6).

$$
\mathrm{E}_{c}=60 \cdot \rho \cdot \alpha \cdot \dot{V}_{d} \cdot\left(h_{m}-h_{s}\right)
$$

Where, $\mathrm{E}_{c}$ is cooling energy consumption, $\alpha$ is minimum air flow ratio, $\dot{V}_{d}$ is design air flow rate of air, $h_{m}$ is mixed air enthalpy, and $h_{s}$ is supply air enthalpy

\subsubsection{Reheating Energy Consumption}

The reheating energy consumption in heating mode can be calculated by Equation (7).

$$
\mathrm{E}_{r h}=60 \cdot \rho \cdot C_{p} \cdot \alpha \cdot \dot{V}_{d} \cdot\left(T_{d i s}-T_{s}\right)
$$

Where, $\mathrm{E}_{r h}$ is reheating energy consumption

\section{Existing Control Method of VAV Terminal Unit 3.1 Simulation Condition}

The TRNSYS 17 simulation program was used to calculate the minimum air flow of the VAV system. ${ }^{11 \text {, }}$ 12), 13) The TRNSYS (transient systems simulation) is a building detailed analysis program and the users perform a simulation by linking the components to each other. In the program, the components that are not in the TRNSYS Library can also be encoded and newly added using FORTRAN. In this respect, TRNSYS is a program with potentially diverse applications. The simulation zone selected was an actual office building. This building is operated as a single duct VAV system and is occupied by two people. The AHU operate economizer, and the zone is a single zone and assumes that it is a closed system. To analyze the stratification, the space was separated into 17 horizontal nodes with $0.2 \mathrm{~m}$ intervals from the bottom. This divided the internal heating elements among each horizontal node. The indoor temperature setpoint was $24^{\circ} \mathrm{C} .{ }^{10)}$

The walls of the simulation model consisted of wood shingle over plywood, polystyrene insulation, and gypboard arranged in the construction shown in Table 2 . The gravel built-up roof contained a combination of polystyrene insulation and plywood sheathing. The model also contained a floor slab made from $0.1 \mathrm{~m}$ of heavy concrete and $6 \mathrm{~mm}$ clear double pane glass windows with a $6 \mathrm{~mm}$ air gap.

\subsection{Case Study of Minimum Air Flow}

The most widely used single maximum control logic was selected as the existing control method of the VAV terminal unit. As shown in Fig.2., CASES $1 \sim 3$ were conducted to determine the problems with the conventional fixed minimum air flow setpoint. An evaluation by comparison was conducted using three different measures. CASE 1 is the minimum air flow that considers the sensible heat. The minimum air flow calculated with the largest heating load was applied to CASE 1. CASE 2 is the minimum air flow that considers stratification. This is the case that increases the minimum air flow without inducing stratification. CASE 3 is the minimum air flow that considers the IAQ. In this case, the air flow that can maintain the indoor $\mathrm{CO}_{2}$ concentration at less than $1,000 \mathrm{ppm}$ is selected as the minimum air flow. The standard for the $\mathrm{CO}_{2}$ concentration was $1,000 \mathrm{ppm}$ based on the IAQ maintenance standards of the 'Indoor Air Quality Control in Public Use Facilities, Etc. Act ${ }^{14)}$. Table 3. lists the minimum air flow of each CASE.

\begin{tabular}{|c|c|c|}
\hline \multicolumn{2}{|l|}{ List } & Contents \\
\hline \multirow{3}{*}{ Zone } & Location & Omaha, Nebraska, USA \\
\hline & Use & Office \\
\hline & Size & $6.3 \mathrm{~m} * 2.7 \mathrm{~m} * 3.35 \mathrm{~m}(\mathrm{~L} * \mathrm{~W} * \mathrm{H})$ \\
\hline \multicolumn{2}{|l|}{ System } & VAV with reheat system \\
\hline \multicolumn{2}{|l|}{ People } & 2 people \\
\hline \multirow{2}{*}{$\begin{array}{l}\text { Operating } \\
\text { conditions }\end{array}$} & Schedule & 24hour \\
\hline & $\begin{array}{l}\text { Set point } \\
\text { temperature }\end{array}$ & $24^{\circ} \mathrm{C}$ \\
\hline \multirow{3}{*}{$\begin{array}{l}\text { Load } \\
\text { conditions }\end{array}$} & Occupant & $\begin{array}{l}\text { - Seated, Light work, typing : } \\
150 \mathrm{~W} \\
\text { - Occupants : } 2\end{array}$ \\
\hline & Light & $13 \mathrm{~W} / \mathrm{m}^{2}$ \\
\hline & Equipment & $16 \mathrm{~W} / \mathrm{m}^{2}$ \\
\hline \multirow{3}{*}{$\begin{array}{l}\text { VAV } \\
\text { terminal } \\
\text { unit }\end{array}$} & Model & Staefa \\
\hline & Type & terminal unit with reheat coil \\
\hline & $\begin{array}{l}\text { Maximum } \\
\text { air flow }\end{array}$ & $138 \mathrm{~L} / \mathrm{s}$ \\
\hline
\end{tabular}

Table 1. Simulation Condition

Table 2. Specification of the Material Properties

\begin{tabular}{c|c|c|c|c}
\hline & Construction & $\begin{array}{c}\text { Thick } \\
(\mathrm{m})\end{array}$ & $\begin{array}{c}\text { Conductivity } \\
(\mathrm{W} / \mathrm{mK})\end{array}$ & $\begin{array}{c}\text { Density } \\
\left(\mathrm{kg} / \mathrm{m}^{3}\right)\end{array}$ \\
\hline \multirow{4}{*}{$\begin{array}{c}\text { Exterior } \\
\text { wall }\end{array}$} & $\begin{array}{c}\text { Wood } \\
\text { shingle }\end{array}$ & 0.019 & 0.115 & 513 \\
\cline { 2 - 5 } & Plywood & 0.013 & 0.115 & 545 \\
\cline { 2 - 5 } & Polystyrene & 0.09 & 0.04 & 28 \\
\cline { 2 - 5 } & Gypboard & 0.012 & 0.16 & 801 \\
\hline \multirow{2}{*}{$\begin{array}{c}\text { Interior } \\
\text { wall }\end{array}$} & Gypboard & 0.016 & 0.16 & 801 \\
\cline { 2 - 5 } & Air & 0.022 & - & - \\
\cline { 2 - 5 } & Gypboard & 0.016 & 0.16 & 801 \\
\hline \multirow{3}{*}{ Floor } & $\begin{array}{c}\text { Heavy } \\
\text { concrete }\end{array}$ & 0.1 & 1.6 & 2240 \\
\cline { 2 - 5 } & Polystyrene & 0.09 & 0.04 & 28 \\
\hline
\end{tabular}

Table 3. Simulation CASE

\begin{tabular}{c|l}
\hline CASE & \multicolumn{1}{|c}{ Classification } \\
\hline CASE1 & $\begin{array}{l}\text { Constant minimum air flow setpoint }: 70.5 \mathrm{~L} / \mathrm{s} \\
\text { Minimum air flow considering sensible load }\end{array}$ \\
\hline CASE2 & $\begin{array}{l}\text { Constant minimum air flow setpoint }: 80 \mathrm{~L} / \mathrm{s} \\
\text { Minimum air flow considering stratification }\end{array}$ \\
\hline CASE3 & $\begin{array}{l}\text { Constant minimum air flow setpoint }: 14.1 \mathrm{~L} / \mathrm{s} \\
\text { Minimum air flow considering IAQ }\end{array}$ \\
\hline
\end{tabular}

\subsection{Analysis of Simulation Result}

\section{Analysis of the Indoor Thermal Comfort}

Fig.2. describes the changes in the annual indoor temperature in CASES 1, 2, and 3. CASES 1 and 2 control the annual indoor temperature to $24^{\circ} \mathrm{C}$. In CASE 3, the minimum air flow is so low that the indoor temperature cannot be maintained at a set temperature. 


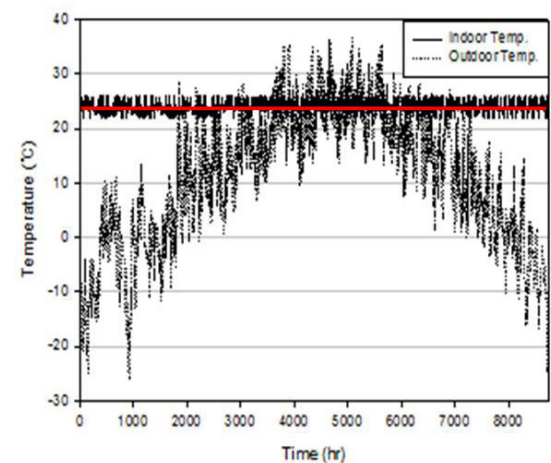

(a) CASE 1

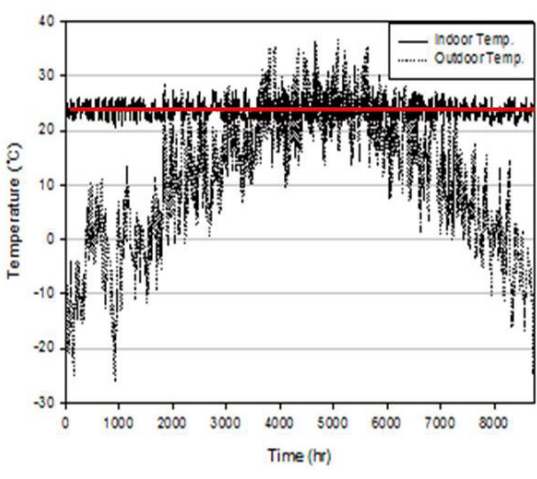

(b) CASE2

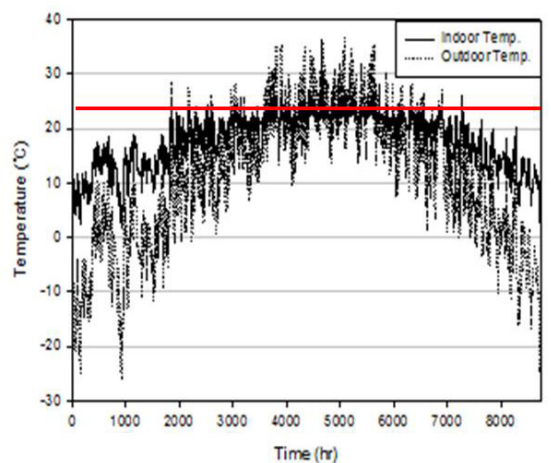

(c) CASE3

Fig.2. Thermal Comfort Analysis Data of the Existing Control Method

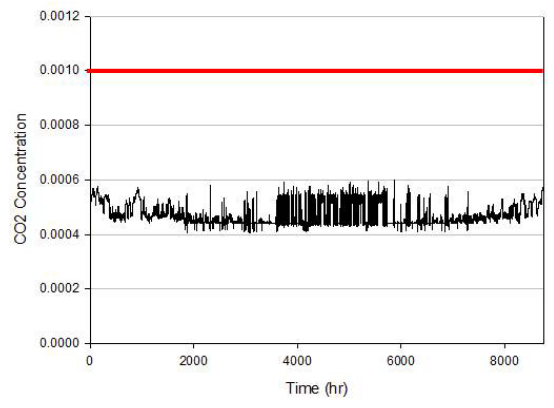

(a) CASE 1

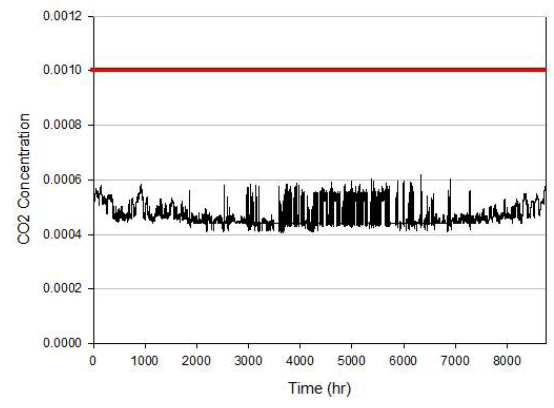

(b) CASE2

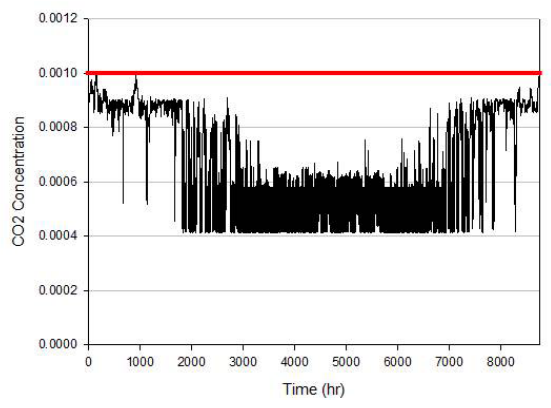

(c) CASE3

Fig.3. Indoor $\mathrm{CO}_{2}$ Concentration Data of the Existing Control Method

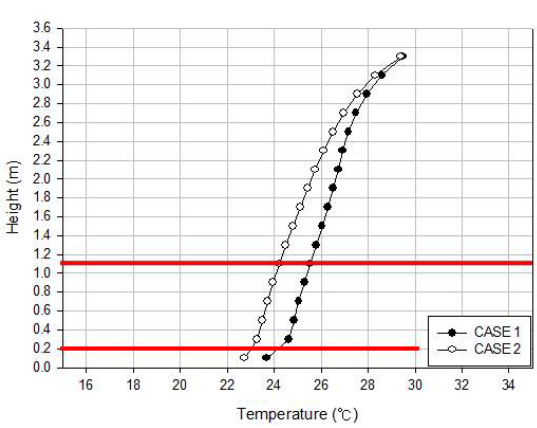

(a) $500 \mathrm{~kJ} / \mathrm{hr}$

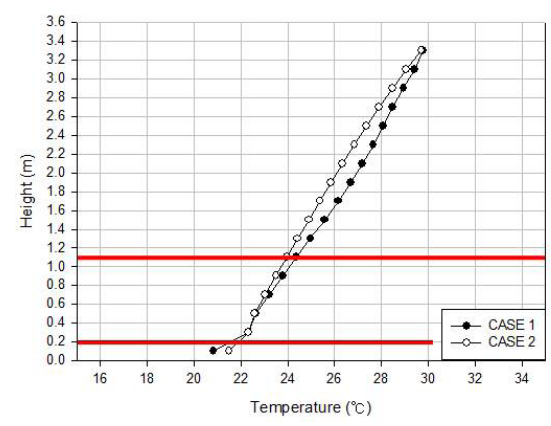

(d) $3000 \mathrm{~kJ} / \mathrm{hr}$

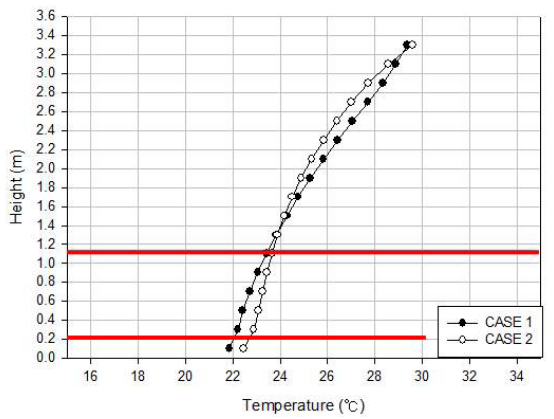

(b) $1000 \mathrm{~kJ} / \mathrm{hr}$

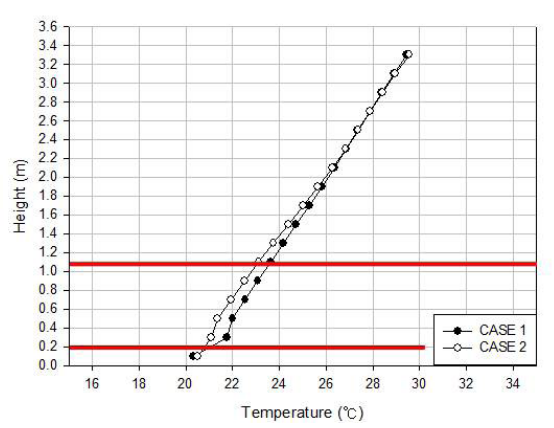

(e) $4000 \mathrm{~kJ} / \mathrm{hr}$

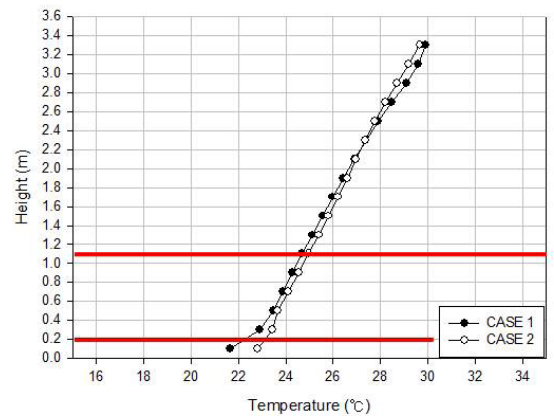

(c) $2500 \mathrm{~kJ} / \mathrm{hr}$

Fig.4. Vertical Room Air Temperature Data of the Existing Control Method 


\section{Analysis of the Indoor Air Quality}

An analysis of the IAQ was conducted based on the indoor $\mathrm{CO}_{2}$ concentration. The standard of the indoor $\mathrm{CO}_{2}$ concentration was set to $1,000 \mathrm{ppm}$ according to the IAQ criterion in the 'Indoor Air Quality Control in Public Use Facilities, Etc. Act'. Fig.3. shows the annual indoor $\mathrm{CO}_{2}$ concentrations in each case. In CASES 1 and 2, the indoor $\mathrm{CO}_{2}$ concentrations were approximately $400 \mathrm{ppm}$ $\sim 600 \mathrm{ppm}$. This figure is lower than the standard. The concentration in CASE 3 was approximately 400ppm $1,000 \mathrm{ppm}$, which meets the IAQ criterion. The indoor $\mathrm{CO}_{2}$ concentration in winter was higher than in summer because of the low minimum air flow rate.

Stratification Analysis

The spread of the indoor vertical temperature was analyzed according to the load condition in each case to determine the stratification. CASE 3 was excluded from stratification analysis because it did not satisfy the indoor temperature. Figs.4.-a and 4.-b describe the spread of the indoor vertical temperature at an indoor load of 500 and $1,000 \mathrm{~kJ} / \mathrm{hr}$, respectively. CASES 1 and 2 met the set temperature at the measurement point of the indoor temperature $(1.1 \mathrm{~m})$. The temperature difference between $0.1 \mathrm{~m}$ from the floor and $1.1 \mathrm{~m}$ from the floor was no higher than $3^{\circ} \mathrm{C}$. In other words, there was no stratification. Figs.4.-c $\sim 4$.-e show the spread of the indoor vertical temperature at an indoor load of 1,500 4,500 kJ/hr. CASES 1 and 2 satisfied the indoor temperature at the measurement point $(1.1 \mathrm{~m})$ under all load conditions. On the other hand, stratification occurred when the temperature difference between $0.1 \mathrm{~m}$ and $1.1 \mathrm{~m}$ from the floor in CASE 1 exceeded $3^{\circ} \mathrm{C}$ at the indoor loads of $2,500 \mathrm{~kJ} / \mathrm{hr}, 3,000$ $\mathrm{kJ} / \mathrm{hr}$ and $4,000 \mathrm{~kJ} / \mathrm{hr}$.

\section{Energy Analysis}

Fig.5. shows the AHU energy consumption according to each case. The heating coil in the AHU showed the largest energy consumption in CASE 3. If the indoor load is small, the minimum necessary outdoor air intake rate is supplied to the room, which increases the heating coil energy. This occurs in CASE 3 , which has a relatively low minimum air flow. The cooling coil energy and fan energy were highest in CASE 2, which has a high minimum air flow. The AHU energy consumption in CASES 1, 2 and 3 was approximately $42,000 \mathrm{MJ}, 52,000 \mathrm{MJ}$ and $61,000 \mathrm{MJ}$, respectively. This shows that, CASE 3 has the largest energy consumption.

The reheating coil energy consumption of the VAV terminal unit in CASES 1, 2 and 3 was approximately $120,000 \mathrm{MJ}, 140,000 \mathrm{MJ}$ and 20,000MJ, respectively. These are related to the size of the minimum air flow.

Fig.7. shows the total energy consumption of AHU and the reheating coil energy. The total energy consumption in CASES 1, 2 and 3 was approximately $160,000 \mathrm{MJ}, 200,000 \mathrm{MJ}$ and $88,000 \mathrm{MJ}$, respectively. CASES 2 and 3 had the largest and smallest energy consumption, respectively.

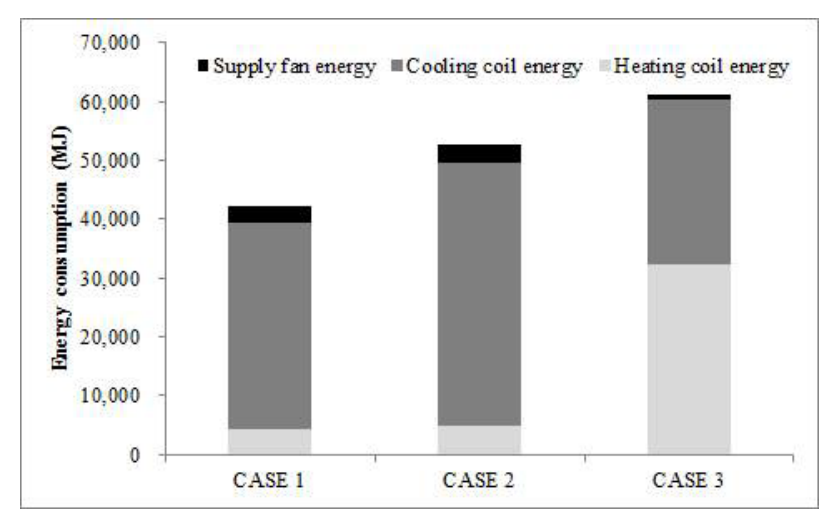

Fig.5. Comparison of the AHU Energy Consumption of the Existing Control Method

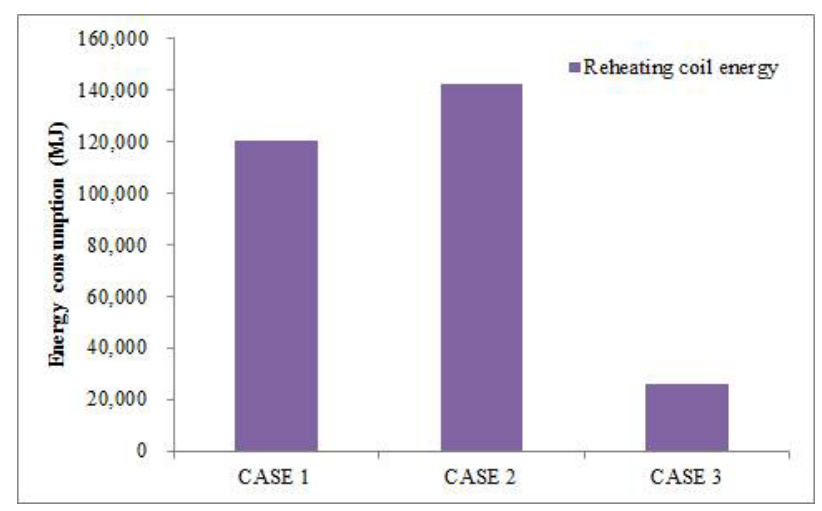

Fig.6. Comparison of the Reheating Coil Energy Consumption of the Existing Control Method

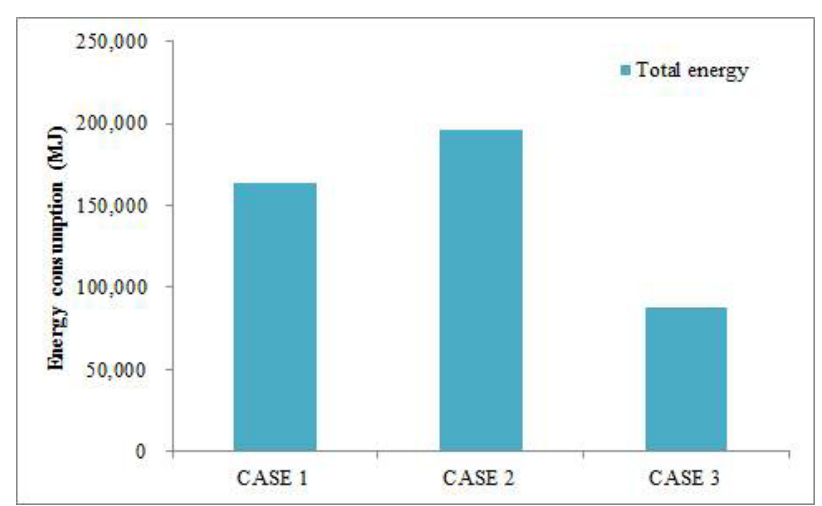

Fig.7. Comparison of the Total Energy Consumption of the Existing Control Method

Fig.8. shows the relation between the outdoor air temperature and supply air flow rate. In winter, most of the air flow rate is supplied to the minimum air flow rate. The energy consumption increases followed by an increase in the minimum air flow rate.

\section{Proposed Control Method of VAV Terminal Unit 4.1 Determination of Minimum Air Flow Without Stratification}

The minimum air flow rate setpoint of the VAV terminal unit should be selected considering stratification. A variable air flow rate will be able to reduce the building energy more than the fixed air 


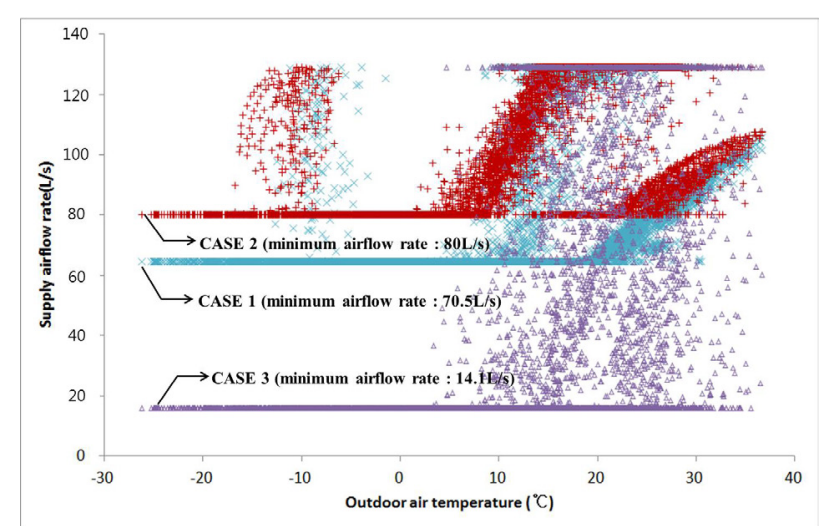

Fig.8. Correction between Outdoor Air Temperature and Supply Air Flow Rate

flow rate. Kang et al. (2014) identified the supply air temperature and air flow rate that will not incur stratification. ${ }^{10)}$ "The relationships among the temperature, air flow, and energy according to the load and indoor vertical temperature difference were analyzed based on the building's ceiling height. The ceiling height of $2.9 \mathrm{~m}, 3.1 \mathrm{~m}, 3.2 \mathrm{~m}$, and $3.35 \mathrm{~m}$ were selected based on the ceiling height of a general office, 2.5-2.7 m. Supply temperatures of $33^{\circ} \mathrm{C}, 34^{\circ} \mathrm{C}, 35^{\circ} \mathrm{C}$, $36^{\circ} \mathrm{C}, 37^{\circ} \mathrm{C}, 38^{\circ} \mathrm{C}, 39^{\circ} \mathrm{C}$ and $40^{\circ} \mathrm{C}$ were selected based on $32.2^{\circ} \mathrm{C}$ (indoor temperature $23.8^{\circ} \mathrm{C}$ ), which was suggested by the ASHRAE Standard 62-2010."

Therefore, this study suggests a stratification control algorithm of the VAV terminal unit that utilized the minimum air flow rate for the load and supply air temperature according to Kang's study. Fig.9. shows the supply air flow rate and temperatures that do not cause stratification according to indoor load. If the load was low, stratification was not observed due to proper indoor temperature control, even though the supply temperature was increased to $40^{\circ} \mathrm{C}$. On the other hand, the supply temperature that did not induce stratification decreased with increasing indoor load.

\subsection{Proposed Algorithm of VAV Terminal Unit}

As shown in Fig.10., the improved case evaluates the variable minimum air flow using the stratification control algorithms. The following is the cooling and heating mode of control algorithms.

\section{Cooling Mode}

The minimum air flow for a cooling load is the air flow required by the room design cooling load. The inlet damper is modulated to maintain the room setpoint between the minimum and maximum air flow setpoint. Heating Mode

The variable minimum air flow can be calculated using the minimum air flow for the heating load. When the room air temperature is below the setpoint, the air flow will decrease as the damper closes towards the minimum air flow setpoint to load, and the discharge air temperature is a variable to meet the room temperature setpoint. Therefore, the minimum air flow should not be constant, but rather should be varied during the heating period.

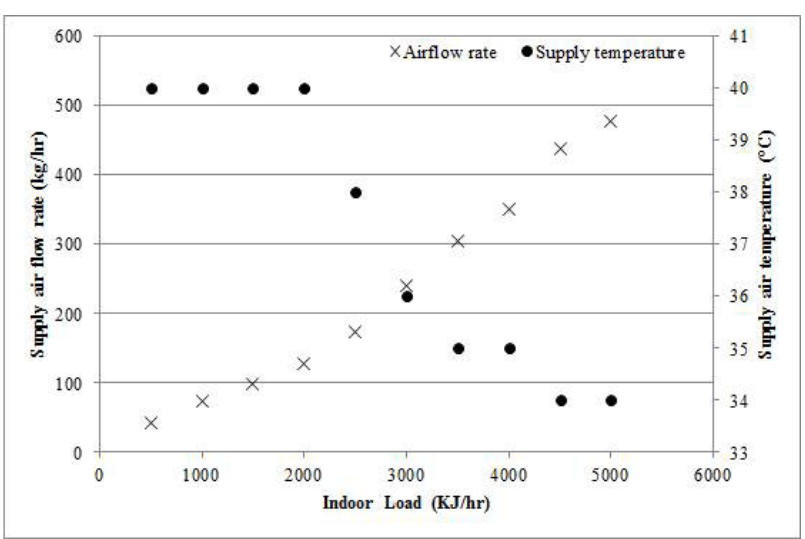

Fig.9. Supply Air Flow Rate and Temperature by Heating Load

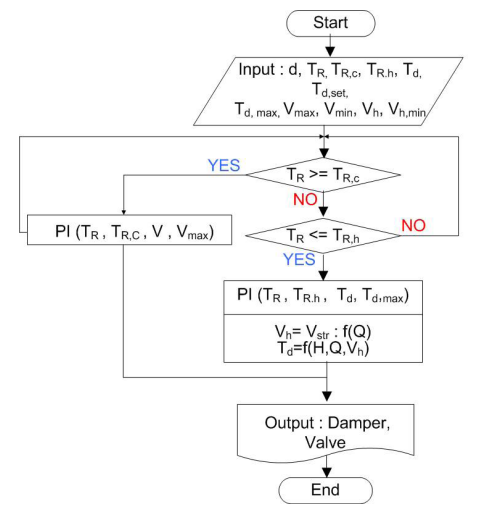

$T_{R}:$ Zone Temperature

$t_{d}$ :Discharge air temperature

$T_{R, C}$ : Room temperature cooling setpoint $T_{R, n}:$ Room temperature heating setpoint d, set: : Discharge air temperature setpoin : Temperature control band $\checkmark$ max:Maximum cooling airflow setpoin $V_{n}:$ Minimum Heating airflow setpoint $V_{\text {str }}$ : Minimum airflow for stratification Q: Heating load d, max: Maximum discharge air temperature

Fig.10. Proposed Control Algorithm of VAV Terminal Unit

\subsection{Results and Discussion}

\subsubsection{Thermal Environment Comfort} Thermal Comfort

Fig.11. shows the annual indoor temperature using the proposed control algorithm in the VAV terminal unit presented. The annual indoor temperature was approximately $23-25^{\circ} \mathrm{C}$, which satisfies the indoor set temperature.

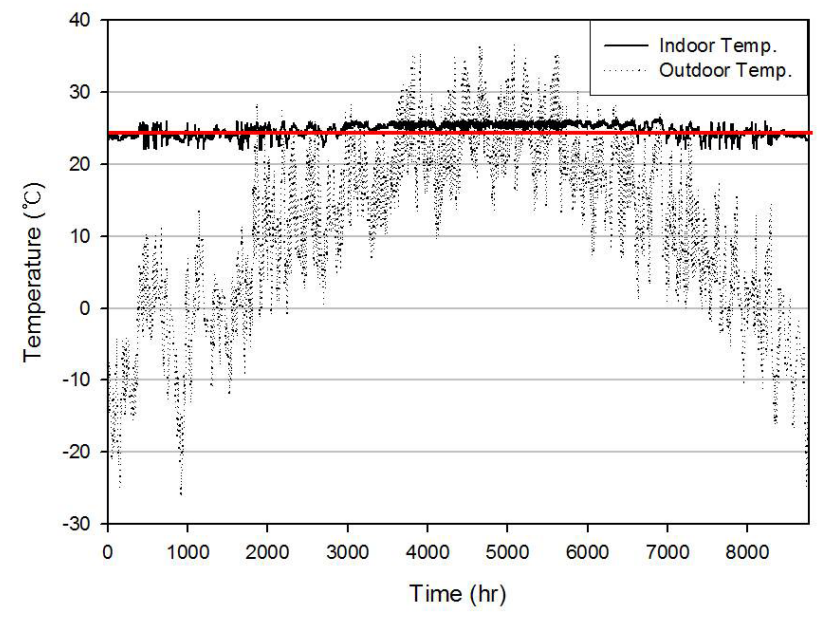

Fig.11. Thermal Comfort Analysis Data of the Proposed Control Method

\section{Indoor $\mathrm{CO}_{2}$ Concentration}

Fig. 12. shows the annual indoor $\mathrm{CO}_{2}$ concentration of the proposed VAV terminal unit control algorithm. The 
indoor $\mathrm{CO}_{2}$ concentration was less than 1000 ppm, which meets the maintenance criterion of the IAQ from 'Indoor Air Quality Control in Public Use Facilities, Etc. Act'.

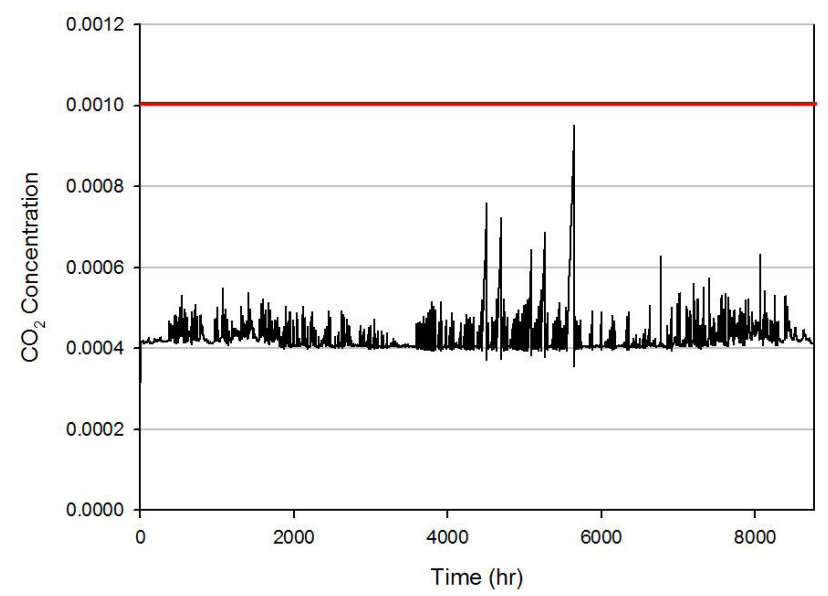

Fig.12. Indoor $\mathrm{CO}_{2}$ Concentration of the Proposed Control Method

\section{Indoor Vertical Temperature Difference}

Stratification was considered to have occurred when the temperature difference between $0.1 \mathrm{~m}$ and $1.1 \mathrm{~m}$ from the floor was more than $3^{\circ} \mathrm{C}$. Fig. 13 shows the indoor vertical temperature difference in the proposed VAV terminal unit control method. Under all load conditions, the algorithm satisfied the indoor set temperature with no stratification.

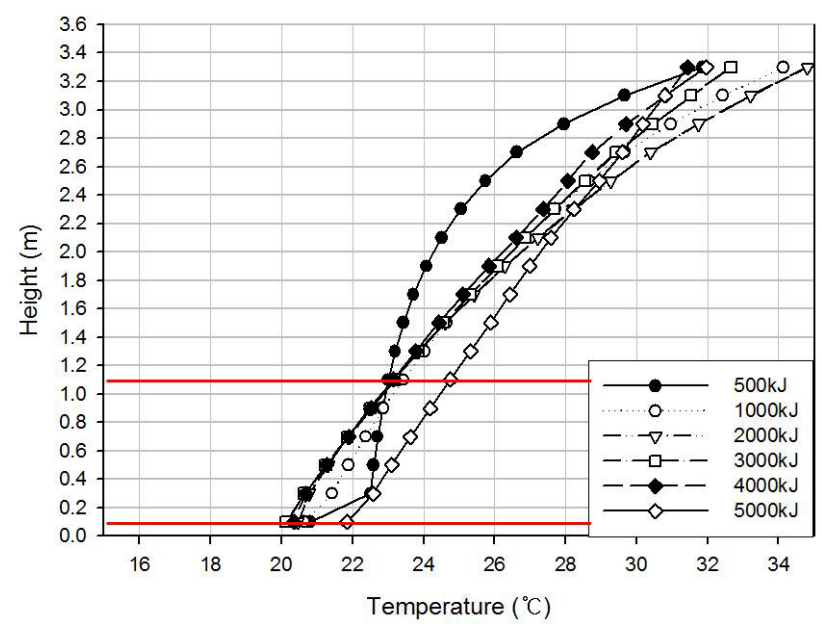

Fig.13. Vertical Room Temperature Data of the Proposed Control Method

\subsubsection{Energy Consumption}

A comparison of the existing control method with the VAV terminal unit control method revealed the minimum air flow that considers stratification. On the other hand, the minimum air flow that considers stratification had a fixed value, which means it sends air at a fixed air flow, even though the indoor load is low. When this occurs, unnecessary fan energy and reheating energy are used, which eventually increases, the overall energy consumption. Accordingly, a new method considering the IAQ and variable minimum air flow depending on the load is presented. In this study, the VAV terminal unit control method was evaluated by energy analysis of the minimum air flow of the existing and improved minimum air flow.

Table 4. Simulation CASE

\begin{tabular}{c|l}
\hline CASE & \multicolumn{1}{|c}{ Classification } \\
\hline $\begin{array}{c}\text { Existing } \\
\text { CASE }\end{array}$ & Constant minimum air flow setpoint $: 80 \mathrm{~L} / \mathrm{s}$ \\
(CASE 2) & Maximum Supply air temperature $: 32.2^{\circ} \mathrm{C}$ \\
\hline Proposed & Variable minimum air flow setpoint \\
CASE & Variable maximum supply air temperature \\
\hline
\end{tabular}

Energy analysis of the existing VAV terminal unit control method and proposed control method presented in this study was conducted. Fig.14. shows the energy consumption of an AHU and a VAV terminal unit in each case. The heating coil energy of the existing CASE and proposed CASE was approximately 4,900 $\mathrm{MJ}$ and 1,600 MJ, respectively. The proposed CASE consumed approximately $67 \%$ less energy than the existing CASE. The cooling coil energy of the existing CASE and proposed CASE was approximately 44,500 $\mathrm{MJ}$ and 35,000 MJ, respectively. The proposed CASE also consumed $21 \%$ less energy than the existing CASE. In the case of the supply fan, the energy consumption of the existing CASE and proposed CASE was approximately 3,300 MJ and 2,800 MJ, respectively. Therefore, the proposed CASE consumed approximately $15 \%$ less energy than the existing CASE. Overall, the total energy consumption of the AHU, including the heating coil, cooling coil and supply fan, was reduced by approximately $13,000 \mathrm{MJ}$, i.e. $25 \%$.

The reheating coil energy of the existing CASE and proposed CASE consumed approximately 141,000 MJ and 75,000 MJ, respectively, showing that the proposed CASE consumed $47 \%$ less energy.

The total energy consumption included the AHU and reheating coil energy consumption. The total energy consumption of the existing CASE and proposed CASE was approximately 196,000 MJ and 115,000 $\mathrm{MJ}$, respectively. The proposed CASE consumed approximately $41 \%$ less energy than the existing CASE.

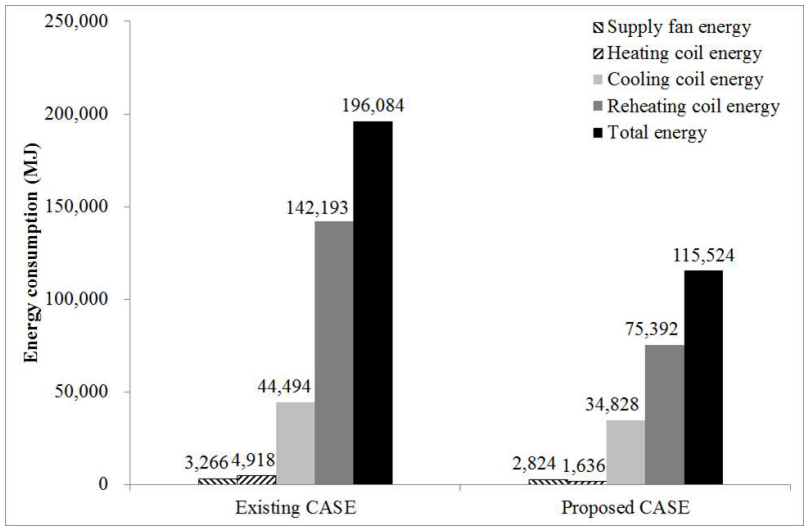

Fig.14. Comparison of the Energy Consumption between the Existing and Proposed Control Method 


\section{Conclusion}

The minimum air flow of the VAV terminal unit is an essential component of indoor thermal comfort, IAQ, stratification, and energy. This study examined the minimum air flow of the VAV terminal unit at an office building. The results were as follows.

(1) The minimum air flows that consider the load, stratification and IAQ were selected after a comparison with the existing fixed minimum air flow control algorithm. Comparison analysis of the indoor thermal comfort, IAQ, stratification, and energy was conducted. The minimum air flow consider of the load was occurred stratification. The minimum air flow considered by the IAQ did not satisfy the indoor set temperature. The minimum air flow considering the load resulted in stratification. The minimum air flow considering stratification had the largest energy consumption but satisfied the indoor temperature and IAQ. As a result, the minimum air flow considering stratification was found to be most appropriate.

(2) The improved control algorithms have a variable minimum air flow and discharge air temperature setpoint without stratification. These algorithms can identify the minimum heating air flow rate and discharge air temperature under indoor load conditions.

(3) The proposed VAV terminal unit control method satisfies all the conditions of indoor thermal comfort, IAQ and stratification. Building energy simulations were performed to evaluate the improved control algorithms with a variable minimum air flow and discharge temperature of energy consumption. The simulation data showed that the variable minimum air flow setpoint exhibited annual energy savings of $40 \%$ compared to the conventional constant minimum air flow setpoint.

\section{Acknowledgements}

This research was supported by a grant (14CTAP-C078946-01) from Infrastructure and transportation technology promotion research Program funded by Ministry of Land, Infrastructure and Transport of Korean government.

\section{References}

1) F. Engdahl, D. Johansson, Optimal supply air temperature with respect to energy use in a variable air volume system, Energy and Buildings 36 (3) (2004), pp.205-218.

2) S.T. Taylor, J. Stein, Sizing VAV boxes, ASHRAE Journal 46 (3) (2004), pp.30-35.

3) Y. Cho, M. Liu, Minimum airflow reset of single duct VAV terminal boxes, Building and Environment 44 (9) (2009), pp.18761885 .

4) ASHRAE, ASHRAE Standard 55-2010 "Thermal environmental conditions for human occupancy", 2010.

5) ASHRAE, ASHRAE Standard 62.1-2010 "Ventilation for acceptable indoor air quality (IAQ)", 2010.
6) H. Wang, Z. Wang, C. Liu, Hot air stratification of ceiling air supply in a large space building, Maximize Comfort: Temperature, Humidity and IAQ 1-5-3 (2006).

7) Y. Cho, M. Liu, Correlation between minimum airflow and discharge air temperature, Building and Environment 45 (2010), pp.1601-1611.

8) E. Liwerant, VAV-box selection, code conformance: demystifying the application of cooling-with-reheat VAV terminals, Heating, Piping, Air Conditioning Engineering 80 (2) (2008), pp.44-46.

9) ASHRAE, ASHRAE Applications Handbook. Chapter 45. Design and application of controls, 2004.

10) Kang S., Kim H., Cho Y. "A Study on the control method of single duct VAV terminal unit through the determination of proper minimum air flow", Energy and Buildings 69 (2014), pp.464-472.

11) X. Jin, H. Ren, X. Xiao, Prediction-based online optimal control of outdoor air of multi-zone VAV air conditioning systems, Energy and Buildings 37 (9) (2005), pp.939-944.

12) Z. Du, X. Jin, X. Yang, A robot fault diagnostic tool for flow rate sensors in air dampers and VAV terminals, Energy and Buildings 41 (3) (2009), pp.279-286.

13) Y. Cho, Development of a terminal control system with variable minimum airflow rate, Energies 5 (2012), pp.4643-4664.

14) Ministry of Environment, "Indoor Air Quality Control in Public Use Facilities, Etc, Act.", 2011.

15) Y. Cho, J. Jo, M. Liu, Evaluation of the Impact of Minimum Airflow on the Energy Consumption of single Duct VAV Terminal Boxes, Journal of Asian Architecture and Building Engineering, Vol.13 No. 1 (2014), pp.239-246.

16) Khoo, I., Levermore, G.J., Letherman, K.M., Variable-air-volume terminal units II: dynamic model, Building Services Engineering Research \& Technology, v 19, n 3 (1998), pp.163-169.

17) Na, Y., E. Nam, I. Yang, Life Cycle Cost Analysis of Air Conditioning Systems in a Perimeter Zone for a Variable Air Volume System in Office Buildings, Journal of Asian Architecture and Building Engineering, Vol. 9 No. 1 (2010), pp.243-250. 